\title{
The Development of Biosensors and Biochips in IECAS*
}

\author{
Xinxia Cai, Dafu Cui \\ State Key Lab of Transducer Technology \\ Institute of Electronics, Chinese Academy of Sciences (IECAS) \\ P.O. Box 2652, Beijing 100080, China \\ xxcai@mail.ie.ac.cn
}

\begin{abstract}
In this paper, the thin film electrode disposable biosensors capable with low cost, high reliability, robustness, low volume sample and hand-held multichannel meter were developed. Various biomolecules, such as glucose, lactate, b-hydroxybutyrate, cholesterol, hemoglobin and creatine kinase in low volume (less than $3 \mu \mathrm{L}$ ) have been detected. It is significant for the applications in home health care, clinical diagnostics and physiological identification and physical performance of athlete. Biochips based on micro-electro-mechanicalsystems (MEMS) technology supply novel biochemical analytical technologies, which offer many advantages including high sample throughput, high integration, and reduced cost. Biochips are rapidly developed in recent years. This paper also will show the research results of biochips based on MEMS technology, including DNA purification chips, DNA-PCR chips, capillary electrophoresis chips, PCR-CE chips, LAPS (light addressable potential sensor) for DNA detection, DNA SPR (surface plasmon resonance) and DNA FET (field effect transistor) sensors. These biochips have potential applications in health care diagnosis, environment monitoring, gene sequencing and high through drug screening.
\end{abstract}

\section{The Research and Development of Biosensors in IECAS}

It is known that biosensors will be integrated and miniaturized, and be used to replace existing, more time consuming analytical methods for monitoring and detecting [1, 2]. In this work, the thin film electrode biosensors with 2-electrode construction and hand-held meter were developed. The surface of the working electrode of the biosensor, modified with nanoscale materials of electrodeposited platinum or carboxymethylcellulose $(\mathrm{CMC})$, has the porous performance and has excellent hydrophilicity, thus the electrode possesses huge surface and high catalytic activities for electrolytic processes.

* This work is supported by the Hi-Tech R. \& D. Program of China (2002AA404510, 2002AA302106), the NSFC (60276039, 20299030, and 60341005), the Chinese Academy of Sciences (KGCX2-SW-602-2), the SRF for ROCS of SEM and the Ministry of Personnel of China. 
Various biomolecules, such as glucose [3], lactate [3], b-hydroxybutyrate [4], cholesterol [4], hemoglobin [7] and creatine kinase [8] in low volume were detected as shown in Table 1[5]. Compared with the strips in market and the existing analytical instruments, the produced disposable biosensors (Figure 1a) are capable with low cost, high reliability, robustness, low volume sample and the created portable multichannel meters (Figure 1b) can be used for test human metabolites without reagents. It is significant for the applications in home health care, clinical diagnostics and physiological identification and physical performance of athlete. Also it has the potential applications in food, beverage, environmental, pharmaceutical, bioprocess and antiterrorism.

Table 1. The biosensors characteristics achieved [5]

\begin{tabular}{|l|l|l|l|l|c|}
\hline \multicolumn{1}{|c|}{ Test Molecules } & $\begin{array}{l}\text { Sample } \\
\text { Solution }\end{array}$ & \multicolumn{1}{|c|}{$\begin{array}{c}\text { Nanoscale } \\
\text { Materials }\end{array}$} & $\begin{array}{c}\text { Test } \\
\text { Time }\end{array}$ & $\begin{array}{c}\text { Measurement } \\
\text { Range }\end{array}$ & $\begin{array}{c}\text { Correlation } \\
\text { Coefficient }\end{array}$ \\
\hline \multirow{2}{*}{ Glucose } & Buffer & Pt nanoparticals & $12 \mathrm{~s}$ & $0.5 \sim 12 \mathrm{mM}$ & 0.998 \\
\cline { 2 - 6 } & Serum & Pt nanoparticals & $27 \mathrm{~s}$ & $1 \sim 30 \mathrm{mM}$ & 0.965 \\
\hline \multirow{2}{*}{ Lactate } & Buffer & Pt nanoparticals & $15 \mathrm{~s}$ & $0.5 \sim 15 \mathrm{mM}$ & 0.998 \\
\cline { 2 - 6 } & Serum & Pt nanoparticals & $25 \mathrm{~s}$ & $0.5 \sim 10 \mathrm{mM}$ & 0.988 \\
\hline hydroxybutyrate & Buffer & Pt nanoparticals & $20 \mathrm{~s}$ & $0.01 \sim 4 \mathrm{mM}$ & 0.999 \\
\cline { 2 - 6 } Cholesterol & Serum & Pt nanoparticals & $20 \mathrm{~s}$ & $0.01 \sim 6 \mathrm{mM}$ & 0.946 \\
\hline \multirow{2}{*}{ Hemoglobin } & Buffer & Pt nanoparticals & $30 \mathrm{~s}$ & $0.1 \sim 5 \mathrm{mM}$ & 0.995 \\
\hline Creatine kinase & Buffer & $\begin{array}{l}\text { Nanoporous } \\
\text { CMC }\end{array}$ & $90 \mathrm{~s}$ & $10 \mu \mathrm{M} \sim 3 \mathrm{mM}$ & 0.995 \\
& & CMC & $140 \mathrm{~s}$ & $8 \sim 800 \mathrm{U} / \mathrm{mL}$ & 0.980 \\
\cline { 3 - 6 } & & $280 \mathrm{~s}$ & $8 \sim 800 \mathrm{U} / \mathrm{L}$ & 0.960 \\
\hline
\end{tabular}

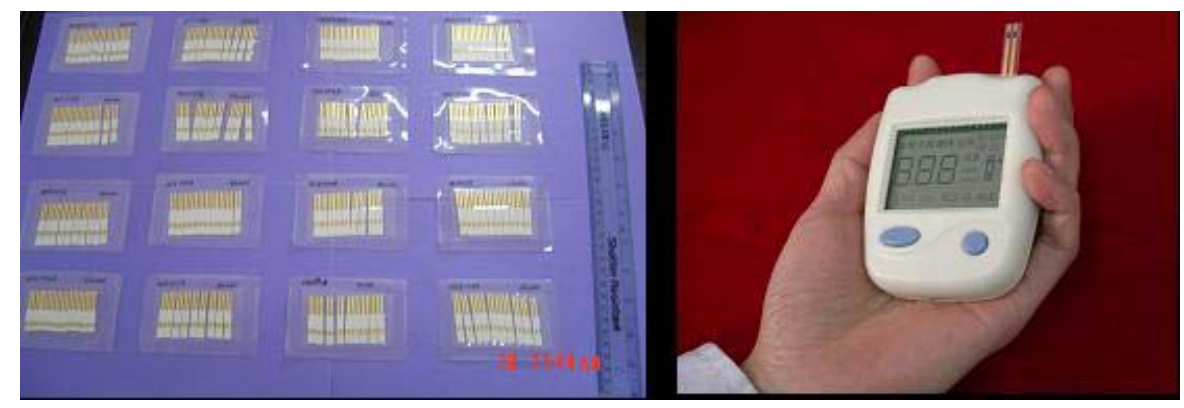

(a)

(b)

Figure 1. The photos of the thin film electrode biosensors fabricated in laboratory throughput and the meter: (a) the disposable biosensors packed in vacuum; (b) the portable multichannel meter. 


\section{Current Research on Biochips in IECAS}

Biochips based on micro-electro-mechanical-systems (MEMS) technology supply novel biochemical analytical technologies, which offer many advantages including high sample throughput, high integration, and reduced cost. Biochips are rapidly developed in recent years [9]. The research results of biochips based on MEMS technology are described as below:

(1) Two types of DNA purification chips based on solid phase extraction (SPE) technology have been fabricated and studied. Both two chips were used to purify the DNA from PCR products. The silicon chip was also used to purify DNA from yeast bacteria.

(2) DNA-PCR chip were fabricated on glass and silicon substrates using MEMS technology (Figure 2a), and a portable temperature controller (Figure 2b) for PCR chip has been developed [10]. PCR reaction has been realized successfully in this system.

(3) PDMS electrophoresis microchip was constructed by molding method. A novel method to fabricate PDMS sandwiched microfluidic chip was presented and the microchip has been demonstrated as a capillary electrophoresis device for double-stranded DNA (dsDNA) and amino acid separation (Figure 3) [11].

(4) Fundamental research of integrated chip, including materials compatibility and microfabricated process possibility has been done. PDMS sandwiched PCR-CE chip and PCR-CE electrochemical detection chip have been designed and microfabricated.

(5) Novel technologies for DNA detection, including light addressable potential sensor (LAPS), SPR sensors and DNA FET, have been developed and good results have been obtained.

The above research on biochips based on MEMS, has laid a foundation for potential applications in health care diagnosis, environment monitoring, gene sequencing and high through drug screening.

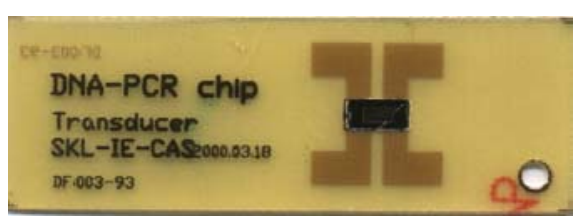

(a)

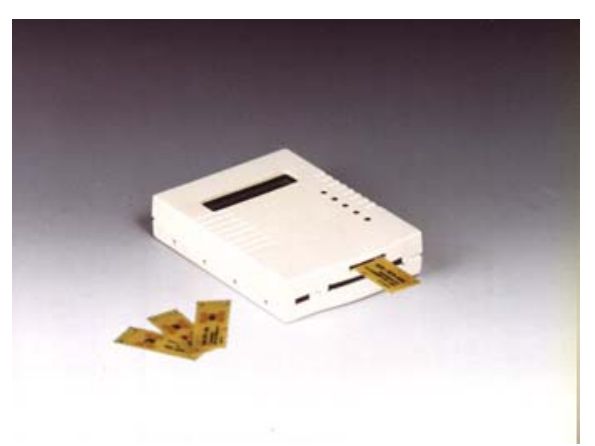

(b)

Figure 2. (a) The mounted chip of DNA-PCR; (b) a photo of the thermal circler. [10] 


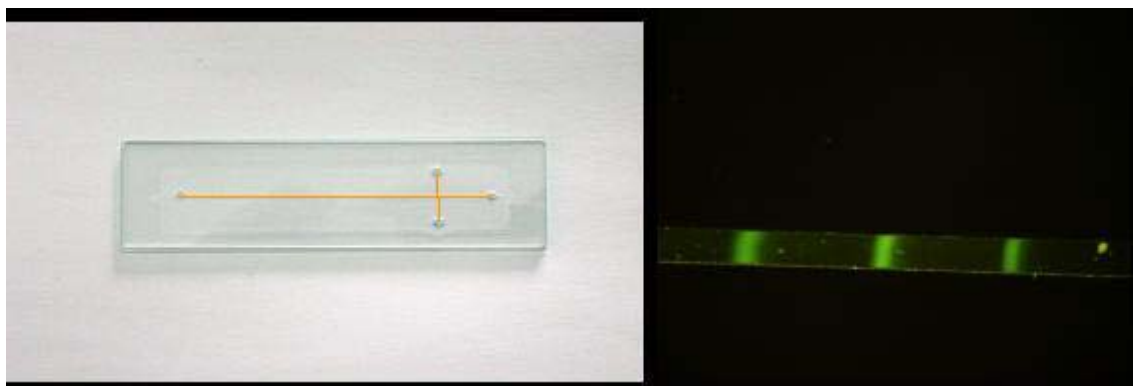

(a)

(b)

Figure 3. (a) The photo of PDMS microchip for DNA separation; (b) the separation image of DNA fragments labeled by SYBR Green I. [11]

\section{References}

1. Cooper, J.M.: Towards Electronic Petri-dishes and Picolitre-scale Single-cell Technologies. Trends in Biotechnology, 17(6), (1999) 226-230.

2. Wang, E.K.: Biosensors. Analytical Chemistry in the $21^{\text {st }}$ Century, Science Press, Beijing (2001) 216-227

3. Nenggao Rao, Rihui Xi, Huaqing Li, Li Wang, Xinxia Cai, Thin-film biosensor array for the determination of glucose and L-lactate, The 6th East Asian Conference on Chemical Sensors, Guilin, China. (2005). Accepted.

4. Li, H., Wang, L., Rao, N., Cui, D., Cai, X.: Thin-film Biosensor Array for Simultaneous Amperometric Measurement of $\beta$-hydroxybutyrate and Cholesterol. The 6th East Asian Conference on Chemical Sensors, Guilin, China. (2005). Accepted.

5. Cai, X.: Thin Film Electrode Biosensors with Nanoscale Materials. The Second International Forum on Post-Genome Technologies (2'IFPT)-Genomic Analysis and Bio-Nanoscience, Nanjing, China, (2004) 231-232.

6. Li, H., Yang, Q., Luo, X., Liu, C., Jiang, L., Cui, D., Cai, X.: Multi-channel Electrochemical Detection System Based on LabView. Proceedings of 2004 International Conference on Information Acquisition. Hefei, China, (2004) 224-227.

7. Jiang, L., Liu, C., Li, H., Luo, X., Wu, Y., Cai, X.: Performance of Amperometric Biosensors for Determination of Hemoglobin, The Second International Forum on PostGenome Technologies (2'IFPT)-Genomic Analysis and Bio-Nanoscience, Nanjing, China, (2004) 287-289.

8. Liu, C., Jiang, L., Li, H., Luo, X., Cai, X.: Measurement of Creatine Kinase Using Disposable Electrochemical Biosensor. The Second International Forum on Post-Genome Technologies (2'IFPT)—Genomic Analysis and Bio-Nanoscience, Nanjing, China, (2004) 277-279.

9. Gregory, T.A. Kovacs: Chemical and Biosensors and Actuators. Micromachined Transducers Sourcebook. McGraw-Hill Companies Inc., (1998)

10. Zhao, Z., Cui, Z., Cui, D., Xia, S.: Monolithically Integrated PCR Biochip for DNA Amplification. Sensors and Actuators A 108 (2003) 162-167.

11. Liu, C., Cui, D.: Separation Imaging of DNA Fragments in Poly (Dimethylsiloxane) Microchip. Proceedings of 2004 International Conference on Information Acquisition, Hefei, China, (2004) 205-207. 